\title{
FL 1060: a new beta-lactam antibiotic with novel properties
}

\author{
D. GREENWOOD AND F. O'GRADY \\ From the Department of Bacteriology, St Bartholomew's Hospital, London
}

SYNOPSIS The effect of FL 1060, a newly described beta-lactam antibiotic, on three strains of Escherichia coli was studied. The agent showed extraordinarily high activity as judged by conventional titrations, but inoculum size, osmolality of the medium, and length of the incubation period were all found to have a marked effect on the result. Continuous turbidimetric monitoring and microscopical observation of cultures of $E$. coli exposed to FL 1060 showed the effect of the antibiotic to have many novel features. Exposed bacterial rods converted to spherical forms, but in a different manner from that of classical penicillin-mediated transformation. Furthermore, although FL 1060 was bactericidal for the majority of the bacterial population, a fraction not only survived its lethal action but grew in high concentrations of the agent thereby producing a phenotypically resistant population which nonetheless continued to show characteristic morphological deformities. Possible reasons for this anomalous behaviour are discussed.

FL 1060, 6-beta-[(Hexahydro-1H-azepin-1-yl)-methyleneamino]-penicillanic acid, is one of a group of new antibiotics developed by Leo Laboratories Ltd (Lund and Tybring, 1972). Antibiotics of this group have the beta-lactam/thiazolidine ring structure of the penicillins, but differ from other betalactam antibiotics in the way the side chain is linked at the 6-amino position of the 6-aminopenicillanic acid molecule. Despite the structural similarity to other beta-lactam antibiotics, FL 1060 has a different antibacterial spectrum with an extremely high level of activity against Escherichia coli and the morphological response of Gram-negative bacilli to the new agent is also different from that seen with other betalactam antibiotics (Lund and Tybring, 1972).

Investigations into the response of Escherichia coli to FL 1060 have revealed that this agent has a number of novel properties which make it unique among beta-lactam antibiotics.

\section{Materials and Methods}

FL 1060 powder was supplied by Leo Laboratories Ltd. Suitable dilutions were made in sterile distilled water and kept at $4^{\circ} \mathrm{C}$ for not longer than five days.

Three strains of $E$. coli sensitive to ampicillin, and

Received for publication 26 October 1972. originally isolated from urinary tract infections, were used.

The broth used contained the following constituents per litre: Casitone pancreatic digest (Difco) $10 \mathrm{~g}$; yeast extract (Difco) $5 \mathrm{~g} ; \mathrm{K}_{2} \mathrm{HPO}_{4} 3 \mathrm{~g} ; \mathrm{KH}_{2} \mathrm{PO}_{4}$ $1 \mathrm{~g}$; glucose $5 \mathrm{~g}$; $\mathrm{NaCl} 5 \mathrm{~g}$. In some experiments the $\mathrm{NaCl}$ was omitted, so lowering the osmolality of the medium from 328 to $170 \mathrm{mOsm} / \mathrm{Kg}$.

Minimum inhibitory concentrations of FL 1060 were estimated by serial doubling dilutions in broth seeded with 1 drop of a four-hour broth culture (to give an inoculum of about $10^{4-5}$ organisms $/ \mathrm{ml}$ ) and incubated overnight at $37^{\circ} \mathrm{C}$.

\section{BACTERICIDAL EFFICACY}

The $E$. coli strains at a concentration of $10^{6}-10^{7}$ organisms $/ \mathrm{ml}$ were exposed to $10 \mu \mathrm{g} / \mathrm{ml}$ FL 1060 in $10 \mathrm{ml}$ broth. Viable counts were performed at appropriate intervals using $0 \cdot 1 \mathrm{ml}$ volumes of serial tenfold dilutions of the exposed culture spread on nutrient agar plates. Counts were then made after overnight incubation of the plates at $37^{\circ} \mathrm{C}$.

\section{OSMOLALITY AND POPULATION DENSITY}

FL 1060 to give a concentration of $10 \mu \mathrm{g} / \mathrm{ml}$ was added to broth and broth from which $\mathrm{NaCl}$ had been omitted. Duplicate $1 \mathrm{ml}$ volumes of these media were seeded with the three $E$. coli strains to give a 
concentration of $10^{4}$ and $10^{6}$ organisms per $\mathrm{ml}$ respectively. The tubes were examined for turbidity after overnight incubation at $37^{\circ} \mathrm{C}$ and again after 48 and 72 hours' incubation.

Experiments were also performed in the continuous opacity monitoring system described by Watson, Gauci, Blache, and O'Grady (1969). Cultures were grown at $37^{\circ} \mathrm{C}$ in the light path of the photometer and antibiotic was added either in the mid-to-late logarithmic phase of growth, or with the bacterial inoculum at the beginning of the experiment. In the latter case an inoculum of about $10^{6}$ organisms per ml (equivalent to the lowest recordable opacity in this system) was used. Osmolality was again varied using broth and salt-free broth.

\section{MORPHOLOGICAL STUDIES}

Broth cultures at $37^{\circ} \mathrm{C}$, monitored photometrically as above, were exposed to FL 1060 during the logarithmic phase of growth and aliquots removed at short intervals for examination by light microscopy. For studies by scanning electron microscopy the bacteria were harvested at appropriate intervals after exposure to antibiotic and fixed directly, without prior washing, in $2 \%$ glutaraldehyde to which $5 \%(\mathrm{w} / \mathrm{v})$ sucrose was added as an osmotic stabilizer. After fixation for two hours the bacterial suspensions were prepared for scanning electron microscopy as previously described (Greenwood and O'Grady, 1969a).

\section{Results}

The minimum inhibitory concentration of FL 1060 for each of the three E. coli strains was found to be $0.125 \mu \mathrm{g}$ per $\mathrm{ml}$ after overnight incubation, but further incubation for 48 to $72 \mathrm{hr}$ yielded visible growth, even at a concentration of $125 \mu \mathrm{g} / \mathrm{ml}$. Microscopical examination of these cultures revealed that the turbidity was due to pleomorphic, mainly spherical, cells which promptly reverted to bacillary form on the first subculture in antibiotic-free broth. The immediate subcultures retained, however, the high level of resistance, but this progressively declined on daily subcultivation in broth until the original sensitivity was regained after about eight passages. Despite this sustained resistance according to the criteria of growth in tube titrations of FL 1060, microscopy revealed that the susceptibility of the bacteria to morphological damage by low concentrations of FL 1060 was never lost.

\section{BACTERICIDAL EFFICACY}

The results of sequential viable counts on the three strains of $E$. coli following exposure to $10 \mu \mathrm{g} / \mathrm{ml}$ FL 1060 are shown in Figure 1. After a time lag of one hour there was a rapid decline in viable count

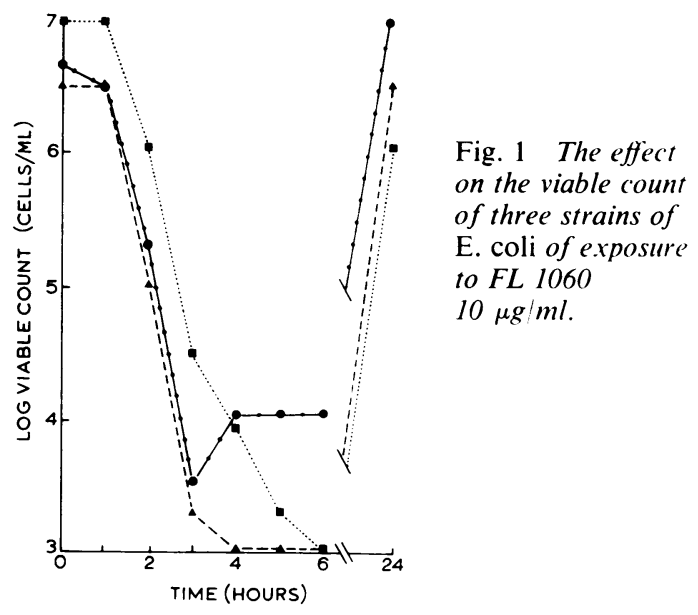

with recovery within 24 hours' incubation of the relatively high bacterial numbers originally inoculated.

OSMOLALITY AND POPULATION DENSITY

As shown in the Table, both these parameters affected the ability of $E$. coli to grow on prolonged incubation in the presence of the agent. Although in all cases increasing the osmolality and size of the inoculum shortened the interval before regrowth occurred, the times taken by the three strains differed considerably: for example, regrowth to a dense turbidity from an inoculum of $10^{4}$ organisms $/ \mathrm{ml}$ in a medium of relatively high osmolality required $24 \mathrm{hr}$ in the case of strain 1; $48 \mathrm{hr}$, strain 2; and $72 \mathrm{hr}$, strain 3 .

\begin{tabular}{|c|c|c|c|c|c|}
\hline \multirow{3}{*}{$\begin{array}{l}\text { Strain of } \\
\text { E. coli }\end{array}$} & \multirow{3}{*}{$\begin{array}{l}\text { Incubation } \\
\text { Period (hr) }\end{array}$} & \multicolumn{4}{|c|}{ Visible Turbidity after Incubation in Broth } \\
\hline & & \multicolumn{2}{|c|}{$\begin{array}{l}\text { Without Added Salt } \\
\text { Inoculated with }\end{array}$} & \multicolumn{2}{|c|}{$\begin{array}{l}\text { With Added Salt } \\
\text { Inoculated with }\end{array}$} \\
\hline & & $\begin{array}{l}\text { I04 orgsi } \\
\mathrm{ml}\end{array}$ & $\begin{array}{l}10^{6} \text { orgs } / \\
\mathrm{ml}\end{array}$ & $\begin{array}{l}10^{4} \text { orgs } 1 \\
\mathrm{ml}\end{array}$ & $\begin{array}{l}10^{6} \text { orgs } \\
\mathrm{ml}\end{array}$ \\
\hline 1 & $\begin{array}{l}24 \\
48\end{array}$ & $\begin{array}{l}0 \\
-\ldots\end{array}$ & $\pm \ldots$ & $\begin{array}{l}-++ \\
\div+\cdots\end{array}$ & $\begin{array}{l}+\div \\
+\div\end{array}$ \\
\hline 2 & $\begin{array}{l}24 \\
48\end{array}$ & 0 & 0 & 0 & $\begin{array}{l}+\div+ \\
++\cdots\end{array}$ \\
\hline 3 & $\begin{array}{l}24 \\
48 \\
72\end{array}$ & $\begin{array}{l}0 \\
0 \\
\rightarrow \cdots\end{array}$ & $\begin{array}{l}0 \\
- \\
\div+-\end{array}$ & $\begin{array}{l}0 \\
\pm \\
T+T\end{array}$ & $\begin{array}{l}\rightarrow \\
+\cdots \\
+\cdots\end{array}$ \\
\hline
\end{tabular}

Table Inhibition patterns of three ampicillin-sensitive strains of E. coli by $10 \mu \mathrm{g} / \mathrm{ml} \mathrm{FL} 1060$ after $24 \mathrm{hr}, 48 \mathrm{hr}$. and $72 \mathrm{hr}$ incubation in media of different osmolality using high and low inocula

The behaviour of the $E$. coli strains in the continuous opacity monitoring system is shown in Figures 2-3. The normal growth curve of these strains was virtually identical and is illustrated in Figure 2A. The addition of $10 \mu \mathrm{g} / \mathrm{ml}$ FL 1060 (80 


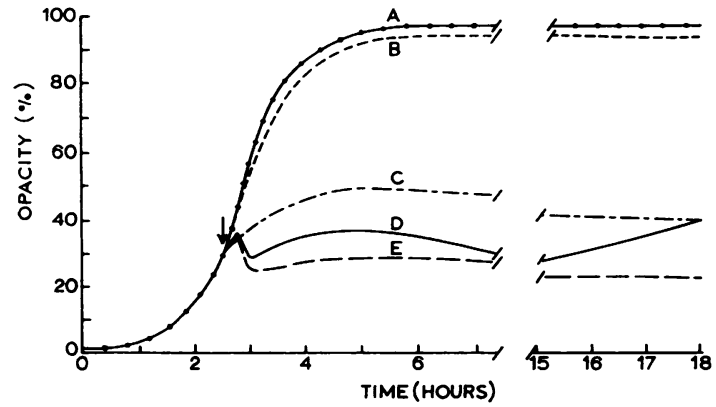

Fig. 2 Continuous opacity records of three strains of E. coli: A normal growth curve of all three strains; B effect of addition (at arrow) of FL 1060, $10 \mu \mathrm{g} / \mathrm{ml}$ to all three strains in broth of osmolality $328 \mathrm{mOsm} / \mathrm{kg}$; C-E effect on each of the strains of a similar antibiotic addition in broth of osmolality $170 \mathrm{mOsm} / \mathrm{kg}$.

MIC) in the mid-to-late logarithmic phase of growth produced no significant deviation from the normal growth curve with any of the three strains (Fig. 2B) although microscopical examination showed the morphological change to the spherical form described by Lund and Tybring (1972). A similar addition of FL 1060 to cultures growing in broth of low osmolality showed a different pattern of response with each strain (Fig. 2C-E). E. coli 1 showed an immediate deviation from the normal growth curve, but the opacity continued to increase for several hours before a slow, prolonged fall in opacity occurred. With the other two strains there was a substantial fall in opacity about five minutes after the addition of the antibiotic followed by a phase, more marked with $E$. coli 2 , in which the opacity rose for a time before gradually falling again. Under these conditions regrowth after overnight incubation was only seen with $E$. coli 2 . In experiments in which broth (with salt) containing $10 \mu \mathrm{g} / \mathrm{ml} \mathrm{FL} 1060$ was seeded with the $E$. coli strains to give a bacterial concentration of about $10^{6}$ organisms per ml (which approximates to the lower limit of recordable turbidity in this system), the three strains all showed a fall in opacity after a period lasting about two $\mathrm{hr}$ in which the turbidity substantially increased (Fig. $3 \mathrm{~A}-\mathrm{C})$. The extent of the turbidity increase as well as the subsequent lysis varied with the three strains and regrowth occurred in all these experiments at a variable time after the lytic phase, depending on the strain used. When this experiment was repeated using salt-free broth as growth medium, a similar, but diminished, opacity increase was seen in each case and regrowth was much delayed, taking as long as $50 \mathrm{hr}$ with strain $E$. coli 3 (Fig. 3D-F). Microscopical examination of the cultures demonstrated that the characteristic FL 1060-induced morphology was maintained for the duration of theexperiments in all cases.

Preliminary results with other strains suggest that the different behaviour of our strains $E$. coli 1 and $E$. coli 3 typify two extremes of a spectrum of response among sensitive Escherichia strains.

\section{MORPHOLOGICAL STUDIES}

The appearance of normal cells of one of the $E$. coli strains in the scanning electron microscope is shown in Figure 4. The transformation of the bacterial cells to spherical form over a two-hr period under the influence of $10 \mu \mathrm{g} / \mathrm{ml} \mathrm{FL} 1060$ is illustrated in Figures 5-7. The bacteria first underwent generalized surface changes leading to the formation of cells with irregular surfaces (Fig. 5); on further incubation these appeared to divide and the two halves of the dividing cells slowly rounded up (Fig. 6) until the

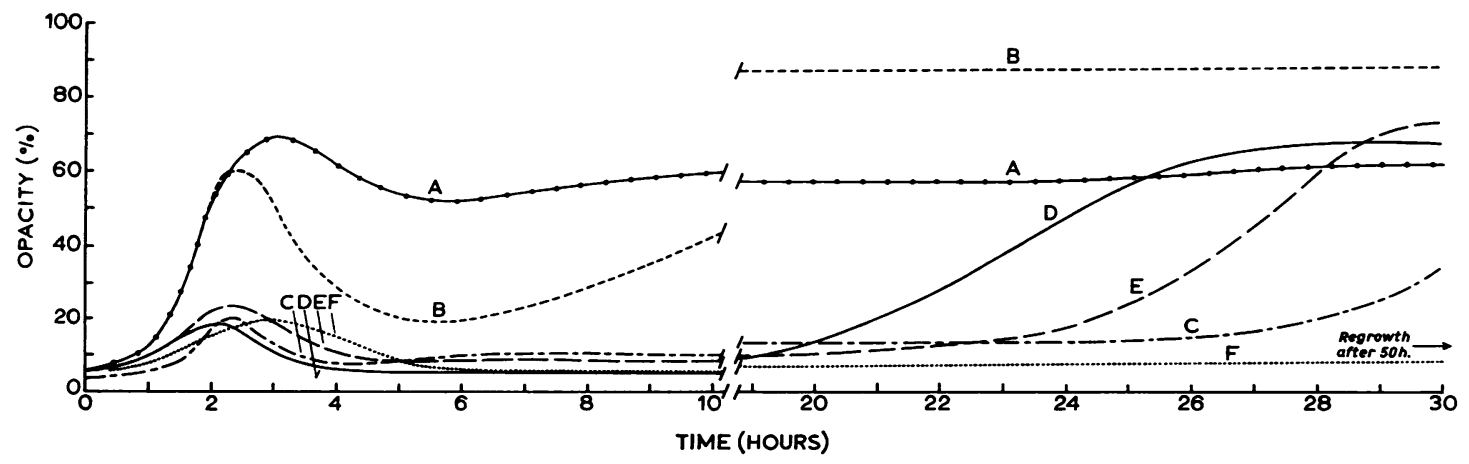

Fig. 3 Continuous opacity records of E. coli strains inoculated into broth containing FL $1060,10 \mu \mathrm{g} / \mathrm{ml}$, to give a bacterial concentration of about $10^{6} \mathrm{orgs} / \mathrm{ml}$. A-C: broth of osmolality $328 \mathrm{mOsm} / \mathrm{kg} ; \mathrm{D}-\mathrm{F}:$ broth of osmolality 170 mOsm/kg. A, D: E. coli strain 1; B, E: E. coli strain 2; C, F: E. coli strain 3. 


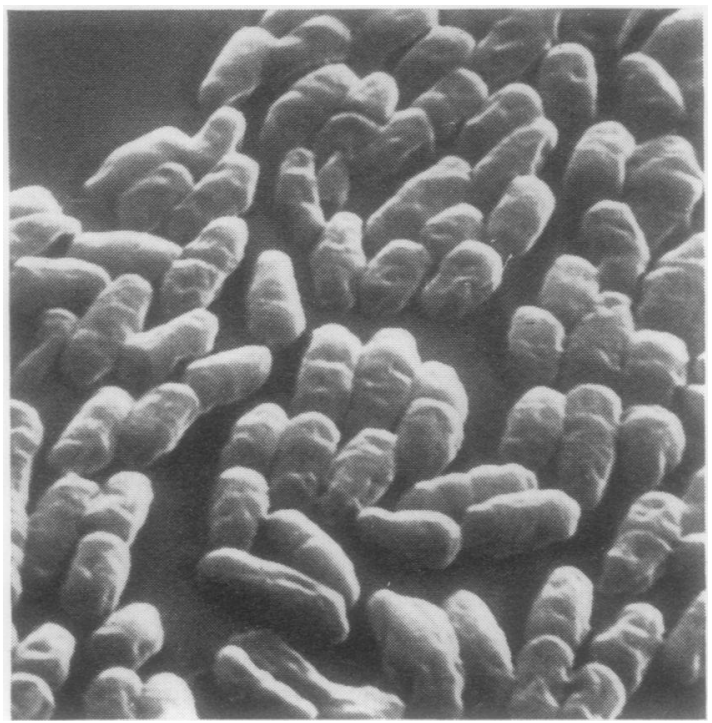

Fig. 4 Escherichia coli. Normal forms from exponentially growing culture. Scanning electron micrograph

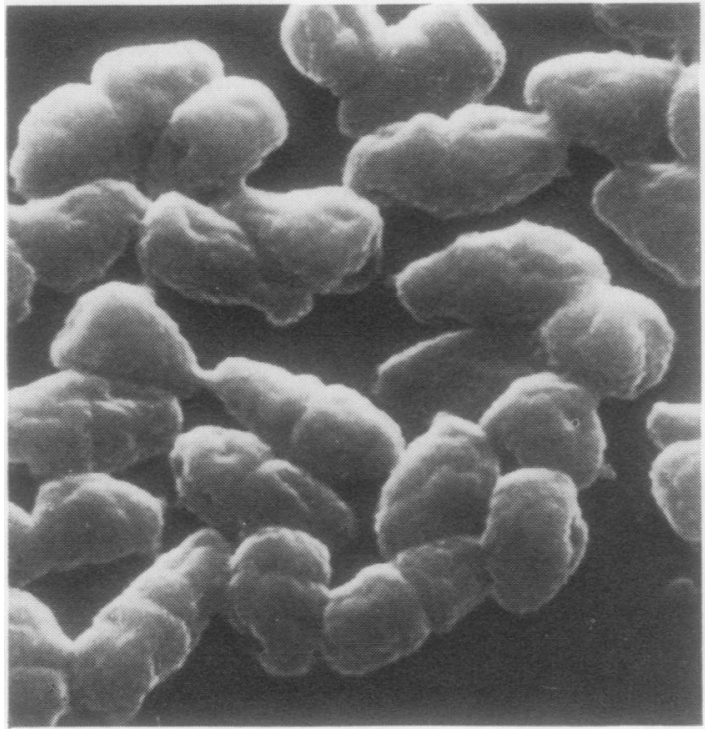

Fig. 6

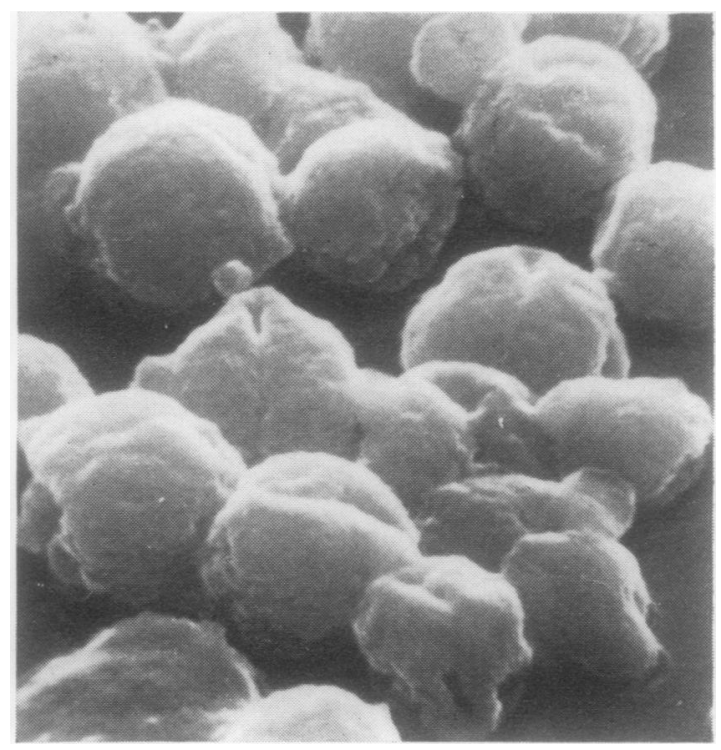

Fig. 7

Fig. 6 E. coli exposed to $F L 1060,10 \mu \mathrm{g} / \mathrm{ml}$ for $60 \mathrm{~min}$. SEM $\times 12000$.

Fig. 7 E. coli exposed to $F L 1060,10 \mu \mathrm{g} / \mathrm{ml}$ for $120 \mathrm{~min}$. SEM $\times 12000$.

D. Greenwood and F. O'Grady'

Fig. 4

Fig. 5 $(S E M) \times 19000$.

Fig. 5 E. coli exposed to FL $1060,10 \mu \mathrm{g} / \mathrm{ml}$ for $30 \mathrm{~min}$. SEM $\therefore 9700$.

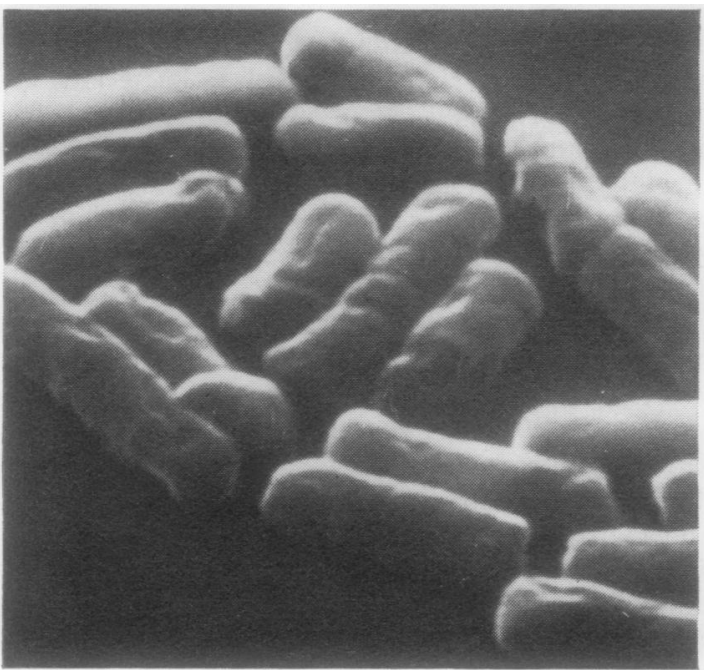

Fig. 5 E. coli exposed to FL 1060, $10 \mathrm{\mu g} / \mathrm{ml}$ for $30 \mathrm{~min}$. SEM $\therefore 9700$. 


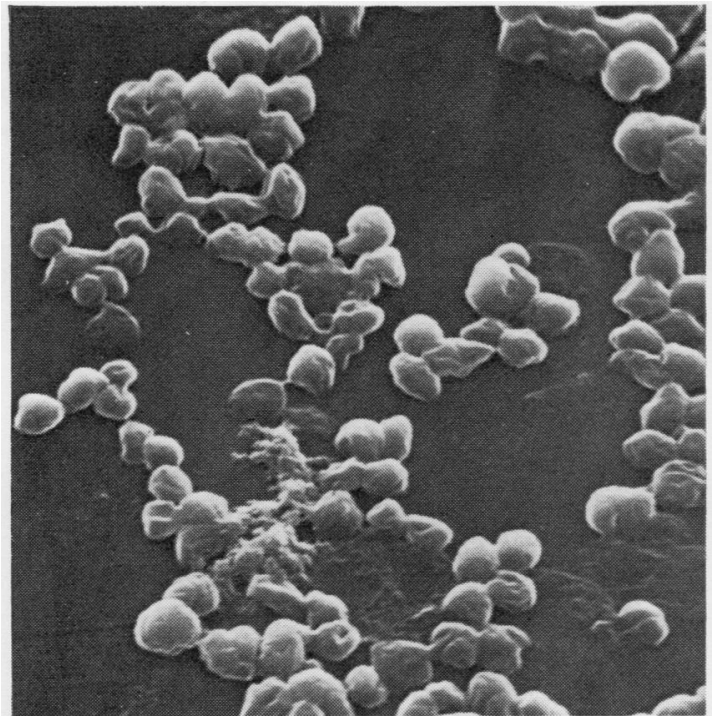

Fig. 8 E. coli exposed to FL 1060, $10 \mu \mathrm{g} / \mathrm{ml}$ overnight showing cell debris and bacteria of abnormal morphology growing in the presence of the antibiotic. SEM $\times 6000$.

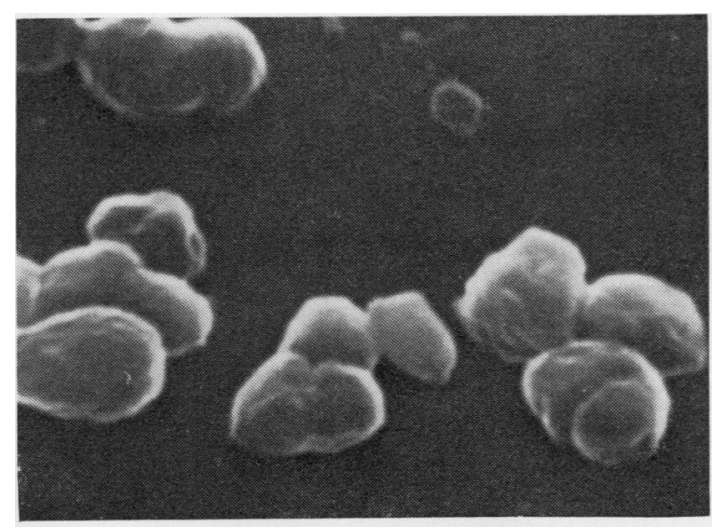

Fig. 9 E. coli exposed to $F L 1060,10 \mu \mathrm{g} / \mathrm{ml}$ overnight showing asymmetrically dividing bacteria. SEM $\times$ 15000 .

culture consisted of spherical cells, much increased in volume, with irregular, pitted surfaces (Fig. 7).

An examination of cultures incubated for prolonged periods to allow regrowth to occur showed, by scanning electron microscopy, bizarre, pleomorphic cells asymmetrically dividing (Figs. 8 and 9).

\section{Discussion}

The first report of FL 1060 by Lund and Tybring (1972) indicated that this new antibacterial agent has properties making it unusual among beta-lactam antibiotics. As they point out, its spectrum of activity, lying markedly on the Gram-negative side, and the extraordinarily high activity against $E$. coli, are anomalous among penicillins and cephalosporins, and the morphological response of $E$. coli to FL 1060 suggests that its mode of action may differ from that of previous beta-lactam antibiotics.

The present results underline thenovelty of this new antibiotic, but also suggest relationships with other beta-lactam agents. The agent is actively bactericidal, it appears to damage the bacterial cell wall, and its lethal action is influenced by osmolality and associated with lysis of the cultures as is the case with penicillins and cephalosporins. The lytic response is not, however, immediate as it is, for example, with ampicillin (Greenwood and O'Grady, 1970) or cephaloridine (Russell and Fountain, 1970), although partial, fairly rapid lysis of some strains of $E$. coli can be achieved by lowering the osmolality considerably. These responses, observed by turbidimetric methods, are reflected in the morphological response of the organisms which, although totally different from that induced by penicillins (Lederberg, 1956; Greenwood and O'Grady, 1969b), leads to an end-product superficially similar to the spheroplast produced from $E$. coli in conditions of high osmolality. The spherical, generally osmotically fragile, cells generated in the presence of FL 1060 differ from spheroplasts in that some of them not only survive ostensibly adverse osmotic conditions, but actively grow in their spherical form without osmotic protection in media containing high concentrations of the agent. Such cells revert to bacillary shape on subculture, but retain for many generations their resistance to the inhibitory effect of FL 1060 although they continue to exhibit morphological damage on exposure to the agent.

A simple explanation for these phenomena is that a spectrum of osmotic pressures exists within populations of $E$. coli and that the cells which survive have a low internal osmotic pressure. If it is additionally postulated that FL 1060 inhibits surface cell-wall mucopeptide synthesis but not the formation and cleavage of septa involved in cell division, cells with a high internal osmotic pressure would be expected to lyse on exposure to the agent, while those with a low internal pressure would continue to divide while still incurring surface damage. We have recently presented evidence in support of both these postulates. A spectrum of osmotic sensitivities can be demonstrated within populations of penicillin- 
treated Gram-negative enterobacteria (Greenwood and O'Grady, 1972a) and FL 1060 appears in terms of its action to be a 'half-penicillin' in the sense that it lacks the ability, possessed by 'whole' penicillins and cephalosporins, to inhibit cell division (Greenwood and O'Grady, 1972b) - an action believed by Hartmann, Höltje, and Schwarz (1972) to be quite separate from that responsible for inhibition of surface cell-wall synthesis.

Some of our results (Fig. 2B) might be taken to indicate that lysis of $E$. coli by FL 1060 requires conditions of external osmolality much lower than those at which ampicillin is effective (Greenwood and O'Grady, 1972a). However, the nephelometric tracings resulting from exposure to the two agents cannot be directly compared because of the very different morphological effects of their actions. Ampicillin-induced lysis is very rapid (Greenwood and O'Grady, 1970) whereas the onset of lysis by FL 1060 under isosmolal conditions takes more than an hour. In view of this, the result shown in Fig. 2B probably does not represent complete osmotic protection, but insusceptibility due to cessation of growth as the cells enter the stationary phase before sufficient damage has been caused to allow subsequent lysis. When antibiotic was added early (Fig. $3)$, lysis did ensue in medium of relatively high osmolality and with one of the three strains appeared more profound than that which followed antibiotic addition to a denser bacterial culture in medium of low osmolality.

A comparison of the increases in opacity following exposure to FL 1060 in these experiments with the viable count results (Fig. 1) suggests that there is an increase in cell volume without cell division, whereas according to our hypothesis cell division should not be inhibited. The scanning electron micrographs show quite clearly that the bacteria do increase substantially in volume under the influence of FL 1060 , as would be expected if they are eventually to succumb to osmotic lysis, and this alone could account for the increase in opacity following exposure to the antibiotic. However time-lapse photomicrography (L. Tybring, personal communication) shows that $E$. coli exposed to FL 1060 continue to divide and that lysis of the progeny does not always ensue until after the cells have actually separated. A transient increase in cell numbers might well not have been detected by viable counting because of the inherent low accuracy of the method, the inability of the partially damaged cells to form colonies, and, judging by the length of time taken by the phenotypically resistant population to establish itself, the low rate of multiplication of affected cells.

As regards the therapeutic potential of FL 1060. the ready emergence of phenotypically-resistant variants which retain their resistance over many generations appears discouraging. However, it remains to be shown whether such cells, which still incur morphological damage, are susceptible to specific and non-specific host defence mechanisms. An assessment of the activity in vitro of FL 1060 against a wide variety of urinary tract pathogens will be presented separately.

We are indebted to Leo Laboratories Ltd for a grant towards the cost of this work.

\section{References}

Greenwood, D., and O'Grady, F. (1969a). Antibiotic-induced surface changes in microorganisms demonstrated by scanning electron microscopy. Science, 163, 1076-1078.

Greenwood, D., and O'Grady, F. (1969b). A comparison of the effects of ampicillin on Escherichia coli and Proteus mirabilis. J. med. Microbiol., 2, 435-441.

Greenwood, D., and O'Grady, F. (1970). Trimodal response of Escherichia coli and Proteus mirabilis to penicillins. Nature (Lond.), 228, 457-458.

Greenwood, D., and O'Grady, F. (1972a). The effect of osmolality on the response of Escherichia coli and Proteus mirabilis to penicillins. Brit. J. exp. Path., 53, 457-464.

Greenwood, D., and O'Grady, F. (1972b). The two sites of penicillin action in Escherichia coli. In preparation.

Hartmann, R., Höltje, J. V., and Schwarz, U. (1972). Targets of penicillin action in Escherichia coli. Nature (Lond.), 235, 426429.

Lederberg, J. (1956). Bacterial protoplasts induced by penicillin. Proc. nat. Acad. Sci. (Wash.), 42, 574-577.

Lund, F., and Tybring, L. (1972). $6 \beta$-amidinopenicillanic acids-a new group of antibiotics. Nature [new Biol.] Lond., 236, 135137.

Russell, A. D., and Fountain, R. H. (1970). The effect of some cephalosporins on Escherichia coli. Postgrad. med. J., 46, October Suppl., 43-50.

Watson, B. W., Gauci, C. L., Blache, L., and O'Grady, F. W. (1969). A simple turbidity cell for continuously monitoring the growth of bacteria. Phys. in Med. Biol., 14, 555-558. 